\title{
TBHP-mediated highly efficient dehydrogenative cross-oxidative coupling of methylarenes with acetanilides
}

\author{
Cui Chen", Weibing Liu and Peng Zhou
}

\author{
Full Research Paper \\ Address: \\ College of Chemical Engineering, Guangdong University of \\ Petrochemical Technology, 2 Guandu Road, Maoming 525000, P. R. \\ China. Fax: +86-668-2923575; Tel: +86-668-2923444 \\ Email: \\ Cui Chen ${ }^{*}$ - cc161002@gdupt.edu.cn. \\ * Corresponding author \\ Keywords: \\ dehydrogenative cross oxidative coupling; methyl arenes; \\ $\mathrm{N}$-arylbenzamides; TBHP
}

\author{
Beilstein J. Org. Chem. 2016, 12, 2250-2255. \\ doi:10.3762/bjoc. 12.217 \\ Received: 20 August 2016 \\ Accepted: 11 October 2016 \\ Published: 25 October 2016 \\ Associate Editor: J. A. Murphy \\ (c) 2016 Chen et al.; licensee Beilstein-Institut. \\ License and terms: see end of document.
}

\begin{abstract}
A TBHP-mediated dehydrogenative cross-oxidative-coupling approach has been developed for the synthesis of $N$-arylbenzamides from methylarenes and acetanilides. This cross-coupling method is free of transition metal catalysts and ligands, and no extra organic solvents are required, which make it an useful and attractive strategy for the straightforward construction of $\mathrm{C}-\mathrm{N}$ bonds. Besides, this conversion is an important complement to the conventional $\mathrm{C}-\mathrm{N}$ forming strategies.
\end{abstract}

\section{Introduction}

Recently, amides have attracted more and more attention due to their extensive utilization in pharmaceutical and agrochemical applications [1-3], as well as for precursors in organic synthesis for the construction of natural products, polymers and organic materials [4-6]. The database of medicinal chemistry indicates that around $25 \%$ of synthetic drugs contain the amide moiety [7]. What is more, the amide motif has also served as pivotal intermediate to generate several other organic functionalities $[8,9]$. To date, a large number of amidation reactions have been established $[10,11]$, such as the condensation of carboxylic acid derivatives with amines [12], the rearrangement of ketoximes [13], the $\mathrm{C}-\mathrm{N}$ cross coupling between aromatic amides or amines and aryl(pseudo)halides [14,15] or aldehydes [16-20]. However, to the best of our knowledge, the studies of dehydrogenative cross-oxidative-coupling reactions between methylarenes and amines for the formation of amides are rather limited, and which would be an important complement to the conventional $\mathrm{C}-\mathrm{N}$ forming strategies. Herein, we disclose a dehydrogenative $\mathrm{C}-\mathrm{N}$ cross-oxidative-coupling reaction of methylarenes with acetanilides, using TBHP as an oxidant to afford $\mathrm{N}$-arylamides in moderate to good yields (Scheme 1).

\section{Results and Discussion}

We began by studying the reaction of toluene (1a) and acetanilide (2a) as model substrates to identify the optimal conditions (Table 1$)$. In the presence of $\mathrm{I}_{2}(0.1$ equiv) and tertbutyl hydroperoxide (TBHP, 2.0 equiv), the study commenced 


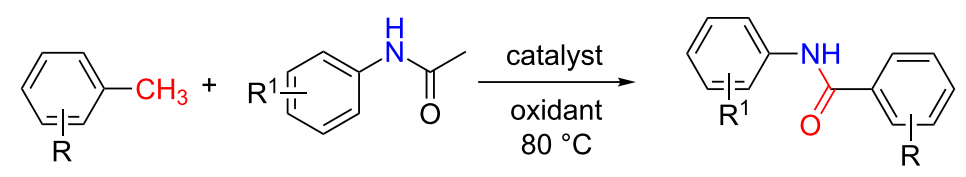

Scheme 1: Synthesis of $N$-arylamides.

to optimize the reaction time (Table 1, entries $1-3$ ). The results show that the reaction was completed after $24 \mathrm{~h}$ and led to the desired $N$-phenylbenzamide 3 aa in $62 \%$ GC yield (Table 1 , entry 2). Disappointingly, other peroxides like di-tert-butylperoxide (DTBP), benzoyl peroxide, dicumyl peroxide (DCP), methyl ethyl ketone peroxide (MEKP), tert-butylperoxy benzoate (TBPB) and cumene hydroperoxide (CHP) proved wholly ineffective for this conversion and no product was observed (Table 1, entries 4-9). Next, the effect of other iodine sources on the reaction was monitored. Pleasingly, ICl and NIS afforded the desired product $\mathbf{3 a a}$ successfully, but led to a marked decrease in yield (Table 1, entries 10 and 11). When the loading of $\mathrm{I}_{2}$ was increased to 1.0 equivalent, a pronounced improvement in the reaction yield was observed (Table 1, entry 12). Further increasing the loading of $I_{2}$ did not show any beneficial effect (Table 1, entry 13). However, the reaction does not occur in the absence of molecular iodine (Table 1, entry 14), which indicates that molecular iodine is requisite for this conversion. We were pleased to find that an excellent product yield of $86 \%$ was obtained (Table 1, entry 15) when increasing the loading of TBHP to 3.0 equivalents. However, decreasing the loading of TBHP to 1.0 equivalent led to a drastic drop in the yield (Table 1, entry 16). It is worth mentioning that this conversion did not show any beneficial effect with nitrogen protection.

After identifying the optimized conditions, we next explored the substrate scope of this transformation. As detailed in Table 2, a wide variety of acetanilides having substituent groups such as methyl, methoxy, ethoxyl, chloro and cyano at different positions were employed to react under the standard conditions. We were pleased to find that all these tested substrates were suc-

Table 1: Optimization studies ${ }^{\mathrm{a}}$.<smiles>Cc1ccccc1</smiles>

$1 a$<smiles>CC(=O)Nc1ccccc1</smiles>

$2 a$

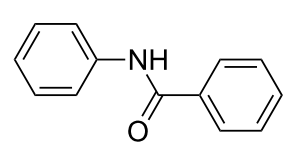

3aa

\begin{tabular}{|c|c|c|c|c|}
\hline Entry & Catalyst (0.1 equiv) & Oxidant (2.0 equiv) & Time (h) & Yield $(\%)^{b}$ \\
\hline 1 & $\mathrm{l}_{2}$ & TBHP & 12 & 47 \\
\hline 2 & $\mathrm{I}_{2}$ & TBHP & 24 & 62 \\
\hline 3 & $\mathrm{I}_{2}$ & TBHP & 36 & 62 \\
\hline 4 & $\mathrm{I}_{2}$ & DTBP & 24 & 0 \\
\hline 5 & $\mathrm{I}_{2}$ & benzoyl peroxide & 24 & 0 \\
\hline 6 & $\mathrm{I}_{2}$ & DCP & 24 & 0 \\
\hline 7 & $\mathrm{I}_{2}$ & MEKP & 24 & 0 \\
\hline 8 & $\mathrm{I}_{2}$ & TBPB & 24 & 0 \\
\hline 9 & $\mathrm{I}_{2}$ & $\mathrm{CHP}$ & 24 & 0 \\
\hline 10 & $\mathrm{ICl}$ & TBHP & 24 & 31 \\
\hline 11 & NIS & TBHP & 24 & 39 \\
\hline $12^{\mathrm{c}}$ & $\mathrm{I}_{2}$ & TBHP & 24 & 71 \\
\hline $13^{d}$ & $\mathrm{I}_{2}$ & TBHP & 24 & 71 \\
\hline 14 & - & TBHP & 24 & - \\
\hline $15^{\mathrm{c}, \mathrm{e}}$ & $\mathrm{I}_{2}$ & TBHP & 24 & 86 \\
\hline $16^{c, f}$ & $\mathrm{I}_{2}$ & TBHP & 24 & 37 \\
\hline
\end{tabular}

aUnless otherwise specified, all the reactions were carried out on $2 \mathrm{a} 0.25 \mathrm{mmol}$ scale, catalyst 0.1 equivalents, oxidant 2.0 equivalents, toluene $2.0 \mathrm{~mL}$; ${ }^{\mathrm{b}} \mathrm{GC}$ yield; ciodine 1.0 equivalents; ${ }^{\mathrm{d}}$ iodine 1.5 equivalents; ${ }^{\mathrm{e}} \mathrm{TBHP} 3.0$ equivalents; ${ }^{\mathrm{f}} \mathrm{TBHP} 1.0$ equivalent. 
cessfully converted into the desired $N$-arylbenzamides 3 . Notably, this conversion appears quite sensitive with respect to the nature (electron-donating or electron-withdrawing) and positions of the substituent groups under the stipulated conditions. para-Methoxy- and para-ethoxy-substituted acetanilides led to a drastic drop in yield as compared to para-cyano- and parachloro-substituted acetanilides (Table 2, entries 5-8). As well as ortho-methyl- and ortho-chloro-substituted substrates also led to a marked decrease in yield as compared to their corresponding para-substituted substrates (Table 2, entries 2, 3, 5, and 9).

Table 2: Scope of the $N$-arylamides ${ }^{a}$.

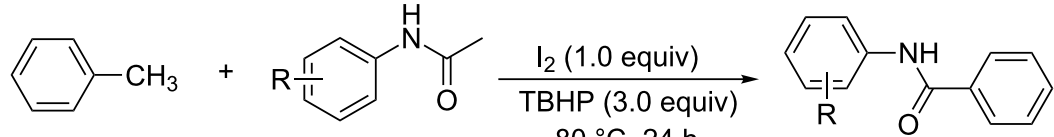

$1 \mathrm{a}$

3

\begin{tabular}{|c|c|c|c|}
\hline Entry & 2 & 3 & Yield $(\%)^{b}$ \\
\hline 1 & & & 80 \\
\hline 2 & & & 75 \\
\hline 3 & & & 72 \\
\hline 4 & & & 81 \\
\hline 5 & & & 83 \\
\hline 6 & & & 63 \\
\hline 7 & & & 62 \\
\hline 8 & & & 85 \\
\hline 9 & & & 71 \\
\hline
\end{tabular}


Table 2: Scope of the $\mathrm{N}$-arylamides ${ }^{\mathrm{a}}$. (continued)

10

11<smiles>Cc1ccc(C)cc1</smiles>

12<smiles>Cc1ccc(C)cc1</smiles>

13<smiles>Cc1ccc(C)cc1</smiles>

14<smiles>Cc1ccc(C)cc1</smiles>

15<smiles>Cc1cccc(C)c1</smiles><smiles>Cc1cccc(C(=O)Nc2ccccc2)c1</smiles><smiles>Cc1ccc(C(=O)Nc2ccccc2)cc1</smiles><smiles>Cc1ccc(NC(=O)c2ccc(C)cc2)cc1</smiles><smiles>Cc1ccc(C(=O)Nc2ccccc2Cl)cc1</smiles><smiles>Cc1ccc(C(=O)Nc2cccc(Cl)c2)cc1</smiles><smiles>COc1ccc(NC(=O)c2ccc(C)cc2)cc1</smiles>

aUnless otherwise specified, all the reactions were carried out on $21.0 \mathrm{mmol}$ scale, $12.0 \mathrm{~mL}$; ${ }^{\text {bisolated yield. }}$

To further extend the adaptability of this transformation, other methyl arenes were also checked under the standard conditions. Pleasingly, $m$-xylene and $p$-xylene afforded the desired product 3 successfully, but in lower yields (Table 2, entries 10 and 11). In the same manner, we next investigated the reactions of $p$-xylene with $N$-phenylacetamide, $N$ - $p$-tolylacetamide, $N$-(4methoxyphenyl)acetamide, $N$-(2-chlorophenyl)acetamide and $N$-(3-chlorophenyl)acetamide under the standard conditions. Gratifyingly, all the tested acetamides reacted with $p$-xylene successfully, offering the desired $N$-arylbenzamides in moderate yields, from $51 \%$ to $69 \%$ (Table 2 , entries $12-14$ ). It is noteworthy that the reactions did not result in the desired product when using aniline and diethylamine as the partners of acetanilide.

In order to gain insight into the nature of this conversion, two experiments were conducted (Scheme 2). With the addition of $\mathrm{Na}_{2} \mathrm{CO}_{3}$ (sodium carbonate) into the reaction between $1 \mathbf{a}$ and 2a, the yield of $\mathbf{3 a a}$ decreased dramatically to $37 \%$, which confirmed that $\mathrm{Na}_{2} \mathrm{CO}_{3}$ has an inhibitory effect for this transformation. At the same time, the radical scavenger TEMPO (2,2,6,6-tetramethylpiperidinoxyl) completely inhibited the reaction and almost no product was obtained. The result indicat- ed that the mechanism may involve a radical pathway. To our delight, reactions using benzaldehyde and 1-(iodomethyl)benzene as the surrogates of toluene afforded 3aa in excellent yields. These results evidence that either 1-(iodomethyl)benzene or benzaldehyde may be the reaction intermediates derived in situ from toluene.

The mechanism for this conversion is unclear. Based on literature reports and our present experimental results, a plausible reaction mechanism has been proposed in Scheme 3 and exemplified by the formation of 3aa. Initially, toluene (1a) reacted with molecular iodine and TBHP to produce the 1-(iodomethyl)benzene (4) and benzaldehyde (5) [21,22]. Intermediate 6 was generated from the coupling of $\mathbf{2 a}$ with intermediate $\mathbf{4}$ [22], by eliminating a molecule of HI. According to the results of the control experiments, intermediate $\mathbf{6}$ also could be obtained from the reaction of benzaldehyde with $\mathbf{2 a}$ under the standard conditions. Then, intermediate $\mathbf{6}$ underwent a sequence of steps including fast oxidation and dehydration to give $N$-acetyl- $N$-phenylbenzamide (8) under the stipulated conditions, similar to the report of An [23]. Finally, the acidic hydrolysis of $N$-acetyl- $N$-phenylbenzamide (8) furnished the final product $N$-phenylbenzamide (3aa). 


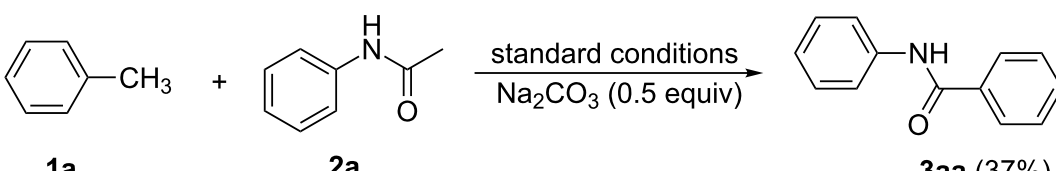

$1 \mathrm{a}$

2a

3aa $(37 \%)$<smiles>Cc1ccccc1</smiles>

1 a<smiles>CC(=O)Nc1ccccc1</smiles>

$2 a$ $\underset{\text { TEMPO }}{\stackrel{\text { standard conditions }}{\longrightarrow}}$<smiles>O=C(Nc1ccccc1)c1ccccc1</smiles>

3aa (trace)<smiles>O=Cc1ccccc1</smiles><smiles>CC(=O)Nc1ccccc1</smiles>

$2 a$

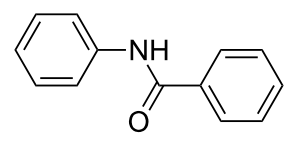

3aa $(86 \%)$<smiles>ICc1ccccc1</smiles><smiles>CC(=O)Nc1ccccc1</smiles>
standard conditions

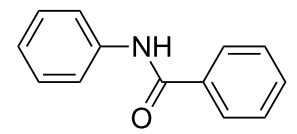

3aa $(82 \%)$

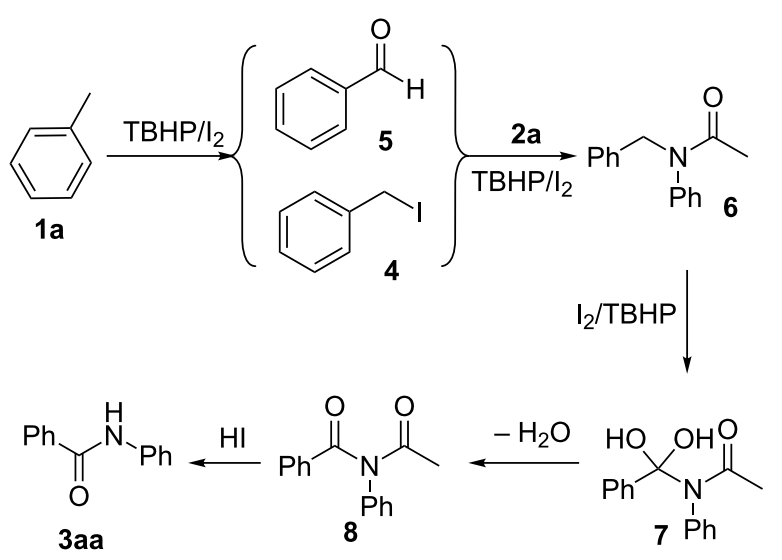

Scheme 3: Plausible mechanism.

\section{Conclusion}

In conclusion, a dehydrogenative $\mathrm{C}-\mathrm{N}$ cross oxidative coupling approach has been developed for the synthesis of $\mathrm{N}$-arylbenzamides from methylarenes and acetanilides. In this protocol, the $\mathrm{C}-\mathrm{N}$ cross oxidative coupling is free of transition metal catalysts, which makes the present method a useful and attractive strategy for the straightforward construction of $\mathrm{C}-\mathrm{N}$ bonds. Besides, this conversion is an important complement to the conventional $\mathrm{C}-\mathrm{N}$ forming strategies. More applications of this novel protocol and the study of the detailed mechanism are currently underway.

\section{Supporting Information}

\section{Supporting Information File 1}

Full experimental details and copies of NMR spectral data. [http://www.beilstein-journals.org/bjoc/content/ supplementary/1860-5397-12-217-S1.pdf]

\section{Acknowledgements}

We thank the Guangdong Provincial Department of Science and Technology (No.916014) and the Department of Education of Guangdong Province (No.916021) for financial support.

\section{References}

1. Ganesh, T.; Jiang, J. X.; Yang, M. S.; Dingledine, R. J. Med. Chem. 2014, 57, 4173. doi:10.1021/jm5000672

2. Valverde, I. E.; Vomstein, S.; Fischer, C. A.; Mascarin, A.; Mindt, T. L. J. Med. Chem. 2015, 58, 7475. doi:10.1021/acs.jmedchem.5b00994

3. Good, J. A. D.; Silver, J.; Núñez-Otero, C.; Bahnan, W.; Krishnan, K. S.; Salin, O.; Engström, P.; Svensson, R.; Artursson, P.; Bergström, S.; Almqvist, F. J. Med. Chem. 2016, 59, 2094. doi:10.1021/acs.jmedchem.5b01759

4. Otrubova, K.; Brown, M.; McCormick, M. S.; Han, G. W.; Cravatt, B. F.; Stevens, R. C.; Lichtman, A. H.; Boger, D. L. J. Am. Chem. Soc. 2013, 135, 6289. doi:10.1021/ja4014997

5. Guo, X. G.; Facchetti, A.; Marks, T. J. Chem. Rev. 2014, 114, 8943. doi:10.1021/cr500225d

6. Martí-Centelles, V.; Burguete, M. I.; Luis, S. V. J. Org. Chem. 2016, 81, 2143. doi:10.1021/acs.joc.5b02676 
7. Racine, E.; Monnier, F.; Vorsb, J. P.; Taillefer, M. Chem. Commun. 2013, 49, 7412. doi:10.1039/c3cc42575d

8. Tobisu, M.; Nakamura, K.; Chatani, N. J. Am. Chem. Soc. 2014, 136, 5587. doi:10.1021/ja501649a

9. Panahi, F.; Jamedi, F.; Iranpoor, N. Eur. J. Org. Chem. 2016, 780. doi:10.1002/ejoc.201501349

10. Zhang, Z. M.; Wu, L. H.; Liao, J. H.; Wu, W. Q.; Jiang, H. F.; Li, J. X.; Li, J. W. J. Org. Chem. 2015, 80, 7594. doi:10.1021/acs.joc.5b01178

11. Zhang, F. L.; Zhu, X.; Chiba, S. Org. Lett. 2015, 17, 3138. doi:10.1021/acs.orglett.5b01458

12. Chen, P. J.; Wang, H. Y.; Peng, A. Y. RSC Adv. 2015, 5, 94328. doi:10.1039/C5RA18459B

13. Babak, K.; Hesam, B. Synlett 2010, 2019. doi:10.1055/s-0030-1258484

14. Dai, H. M.; Yu, C.; Lu, C. S.; Yan, H. Eur. J. Org. Chem. 2016, 1255. doi:10.1002/ejoc.201501551

15. Iranpoor, N.; Panahi, F.; Roozbin, F.; Erfan, S.; Rahimi, S. Eur. J. Org. Chem. 2016, 1781. doi:10.1002/ejoc.201501607

16. Ding, Y. Z.; Zhang, X.; Zhang, D. Y.; Chen, Y. T.; Wu, Z. B.; Wang, P. Y.; Xue, W.; Song, B. A.; Yang, S. Tetrahedron Lett. 2015, 56, 831. doi:10.1016/j.tetlet.2014.12.113

17. Jia, X. F.; Zhang, S. H.; Wang, W. H.; Luo, F.; Cheng, J. Org. Lett. 2009, 11, 3120. doi:10.1021/ol900934g

18. Wu, Y. N.; Li, B. Z.; Mao, F.; Li, X. S.; Kwong, F. Y. Org. Lett. 2011, 13, 3258. doi:10.1021/ol201201a

19. Wang, J.; Liu, C.; Yuan, J. W.; Lei, A. W. Chem. Commun. 2014, 50, 4736. doi:10.1039/c4cc01447b

20. Kumar, S.; Vanjari, R.; Guntreddi, T.; Singh, K. N. RSC Adv. 2015, 5, 9920. doi:10.1039/C4RA15140B

21. Rout, S. K.; Guin, S.; Ali, W.; Gogoi, A.; Patel, B. K. Org. Lett. 2014, 16 , 3086. doi:10.1021/ol5011906

22. Majji, G.; Guin, S.; Gogoi, A.; Rout, S. K.; Patel, B. K. Chem. Commun. 2013, 49, 3031. doi:10.1039/c3cc40832a

23. Zou, Y.; Xiao, J.; Peng, Z. Z.; Dong, W. R.; An, D. L. Chem. Commun. 2015, 51, 14889. doi:10.1039/C5CC05483D

\section{License and Terms}

This is an Open Access article under the terms of the Creative Commons Attribution License (http://creativecommons.org/licenses/by/4.0), which permits unrestricted use, distribution, and reproduction in any medium, provided the original work is properly cited.

The license is subject to the Beilstein Journal of Organic Chemistry terms and conditions:

(http://www.beilstein-journals.org/bjoc)

The definitive version of this article is the electronic one which can be found at: $\underline{\text { doi: } 10.3762 / \text { bjoc. } 12.217}$ 